\title{
Post Traumatic Stress Disorder (PTSD) and It's Associated Factors among Secondary Level Students in Chautara Municipality, Nepal
}

\author{
${ }^{1}$ Trima Gurung, ${ }^{1}$ Damaru Prasad Paneru
}

${ }^{1}$ School of Health and Allied Sciences, Pokhara University

\begin{abstract}
Children and adolescents are more prone to developing Post Traumatic Stress Disorders. Objective of this study was to assess the magnitude of Post Traumatic Stress Disorder and associated factors among secondary level students in Chautara Municipality, Nepal. A cross sectional study was conducted among 249 secondary level students. Data were collected using population proportionate sampling method along with UCLA PTSD RI with 31 questionnaires DSM V tool was used to assess the PTSD symptom. Questionnaire was design to obtain socio demographic factor and earthquake exposure. Factor associated with PTSD development was assessed through chi square and binary logistic regression. Mean age of respondents was $15.42 \pm 1.079$ years. Majority of them were middle adolescents (74.3\%) and 25.7 percent were early adolescents. More than half of respondents were female 54.6 percent. This study revealed that PTSD was found to be among 27(10.8\%) respondents and dissociative subtype PTSD was among 14(5.6\%) respondents. Age was significantly associated with development of PTSD. Earthquake exposures like financial constraints after earthquake food deficiency displacement due to earthquake was the major factors associated with PTSD development. Psychological tutorship for PTSD is found to be protective factors for PTSD development in adolescents. PTSD was quite high among the secondary level students after six month of earthquake in Chautara municipality, Sindupalchwok district and psychological tutorship and humanitarian program for traumatized students could prevent development of PTSD.
\end{abstract}

Key words: Post traumatic stress disorder; Associated factors; Earthquake; Secondary levels students

Corresponding address: Damaru Prasad Paneru, School of Health and Allied Sciences, Pokhara University.

E-mail: damaru.paneru@gmail.com

\section{INTRODUCTION:}

Post Traumatic Stress Disorder (PTSD) is a psychological reaction that occurs after experiencing or witnessing a highly stressing events (as Wartime combat, physical violence, or a disaster) outside the range of the normal human experience and that is usually characterized by depression, anxiety, flashbacks, recurrent nightmares, and avoidance of reminders of the event. ${ }^{1}$ Many people who go through traumatic events have difficulty in adjusting and coping for a while, but they don't have PTSD with time and good self-care, they usually get better. If the symptoms persist for months or even years interfere with the functioning of daily lifestyle is termed as PTSD. Getting effective treatment after PTSD symptoms can be critical to reduce symptoms and improve function. ${ }^{2}$

Latest version of PTSD testing tools (DSM-5) was launched on 2013 with 31 self-administrated questions. PTSD moved from the class of anxiety disorders into a new class of "trauma and stressor-related disorders. ${ }^{3}$

On $25^{\text {th }}$ April 2015, an earthquake with magnitude measuring 7.8 on Richter scale occurred on Barpak, Gorkha mid between Kathmandu and Pokhara city, Nepal. Nine thousand people died and 23,000 were injured, many more displaced. It resulted in more than 300 aftershocks. ${ }^{4,5}$ Sindupalchowk is one of the worst-affected districts due to the earthquake that took place on the 25th April. While the initial epicenter of the earthquake was in Gorkha district, the highest magnitude
(6.7M) aftershock took place in Sindhupalchowk district. Due to the event 3057 people died, 860 were injured and 3000 people remain unaccounted for and almost 63,885 houses are severely and 2,751 houses are moderately damaged. ${ }^{6}$

\section{METHODS}

A cross sectional descriptive study was conducted among 249 secondary level students after six month of earthquake in Chautara municipality, Sindupalchwok district from July 2015 to December 2015. A research proposal including research instrument was submitted to Nepal Health Research Council and District Education office Sindhupalchowk to obtain permission for the study. All eight secondary schools of Chautara municipality were included in the study. Informed consent was obtained from parents and respondents to cooperate with the study. The participants were 249 secondary level students who had experienced from April earthquake.

UCLA PTSD reaction index with 31 self administered questionnaire was used for assessing PTSD symptoms. A complete bio data of each student was obtained with the aid of questionnaire designed to include age, sex, ethnic group, number of siblings and earthquake exposure. Selfadministered questionnaires were distributed to the students and were asked to fill up in school. Each student was briefly 
instructed about the questionnaire and separate arrangement was provided for each of them to fulfill the form. Data were entered in EPI-Data version 3 and was imported to SPSS V16 for analysis. The proportion of PTSD was calculated by using the criteria provided by DSM5 and similarly, the association of variables with PTSD was find out by using chi- square and binary logistic regression.

\section{RESULTS}

\section{Socio-demographic characteristics of students}

Of the total 249 students 185 (74.3\%) were middle adolescents and $185(25.7 \%)$ were early adolescents with mean age of $15.42 \pm 1.079$ years. The total number of male and female were $136(54.6 \%)$ and $113(45.6 \%)$ respectively. About one third (33.7\%) respondents belong to upper caste group followed by 31.7 percent Disadvantaged Janajatis, 27.7 percent relatively advantaged Janajatis percent, 6.0 percent Dalit and 2.0 percent religious minority group. Most of respondent $(92.0 \%)$ have one or more siblings.

Table 1: Socio-demographic characteristics

\begin{tabular}{|c|c|c|}
\hline Characteristics & $\begin{array}{c}\text { No. of students } \\
(\mathrm{N}=249)\end{array}$ & Percent \\
\hline \multicolumn{3}{|l|}{ Mean Age \pm SD $=15 \pm 1.079$} \\
\hline \multicolumn{3}{|l|}{ Age Category } \\
\hline Early adolescents & 64 & 25.7 \\
\hline Middle Adolescents & 185 & 74.3 \\
\hline \multicolumn{3}{|l|}{ Mean Age \pm SD $=15 \pm 1.079$} \\
\hline \multicolumn{3}{|l|}{ Sex } \\
\hline Male & 113 & 45.4 \\
\hline Female & 136 & 54.6 \\
\hline \multicolumn{3}{|l|}{ Caste } \\
\hline Dalit & 15 & 6.0 \\
\hline Disadvantaged Janajatis & 79 & 31.7 \\
\hline Relatively Advantaged Janajatis & 69 & 27.7 \\
\hline Religious Minorities & 2 & 0.8 \\
\hline Upper Caste Group & 85 & 33.7 \\
\hline \multicolumn{3}{|l|}{ Types of School } \\
\hline Public & 243 & 97.6 \\
\hline Private & 6 & 2.4 \\
\hline \multicolumn{3}{|l|}{ Number of Siblings } \\
\hline None & 20 & 8.0 \\
\hline One or More & 229 & 92.0 \\
\hline
\end{tabular}

\section{Earthquake exposures}

Among 249 students 240 (96.4\%) houses were damaged during earthquake of which 85.0 percent of them had structural damage while remaining 15.6 percent had semi structural damaged. Of all students, 215(86.0\%) witnessed injury during earthquake, $186(74.7 \%)$ of students have economical difficulty after earthquake, 133(53.4\%) loss their neighbor, $125(50.2 \%)$ witness burry and $104(41.8 \%)$ respondents witness death. Whereas, 107 (43.5\%) students lost their family/relatives, 95(38.2\%) had no food security after earthquake, $(31.3 \%)$ loss their friends and $(30.5 \%)$ were displaced due to earthquake. Only $29(11.6 \%)$ students were injured and $16(6.4 \%)$ percent were buried during earthquake. One third of students $92(36.9 \%)$ have psychological tutorship for PTSD and 157 (63.1\%) have no access to such tutorship.

Table 2: earthquake exposure

\begin{tabular}{|l|l|l|}
\hline \multicolumn{1}{|c|}{ Characteristics } & \multicolumn{1}{|c|}{$\begin{array}{c}\text { No. of students } \\
(\mathbf{N = 2 4 9 )}\end{array}$} & Percent \\
\hline House Damaged & 240 & 96.4 \\
\hline Witness injury & 215 & 86.0 \\
\hline Economic difficulty & 186 & 74.7 \\
\hline Loss of Neighbor & 133 & 53.4 \\
\hline Witness burry & 125 & 50.2 \\
\hline Loss of family/relatives & 107 & 43.0 \\
\hline Witness death & 104 & 41.85 \\
\hline No Abundance of Food & 95 & 38.2 \\
\hline Loss of friends & 78 & 31.3 \\
\hline Displacement due to earthquake & 76 & 30.5 \\
\hline Injured & 29 & 11.6 \\
\hline Buried & 14 & $5.6 \%$ \\
\hline Psychological tutorship & 92 & $36.9 \%$ \\
\hline
\end{tabular}

\section{PTSD criteria and diagnosis}

Out of 249 respondents 161 (64.4\%) had met the symptoms of Re-experiencing, whereas 143(57.4\%) of student met symptoms avoidance, 148(59.4\%) of respondents met category of Negative cognition and mood, 76(30.5\%) of student met symptoms of Arousal. An entire respondents had symptoms present for more than one month. Clinically significant distress was met by $93(37.3 \%)$ of total participants. One out of every ten respondents 27(10.8) has PTSD and $14(5.6 \%)$ of them have co morbid disorder with dissociative subtype.

Table 3: PTSD criteria and diagnosis

\begin{tabular}{|l|c|c|}
\hline \multicolumn{1}{|c|}{ Characteristics } & No. of students (N=240) & Percent \\
\hline Re-experiencing & 161 & 64.7 \\
\hline Avoidance & 143 & 57.4 \\
\hline Negative Cognition and Mood & 148 & 59.4 \\
\hline Arousal & 76 & 30.5 \\
\hline Clinical significant distress & 93 & 37.3 \\
\hline Dissociative subtype & 176 & 70.7 \\
\hline PTSD & 27 & 10.8 \\
\hline PTSD with dissociative subtype & 14 & 5.6 \\
\hline
\end{tabular}

Association of PTSD with different factors

It was found that those early adolescents are 2.615(CI=1.525.3939. $\mathrm{P}=0.018$ ) times greater in risk than middle adolescent respondents and the respondents who have economic difficulty in their homes after earthquake are $0.855(\mathrm{CI}=0.806$ $0.907, \mathrm{P}=0.001$ ) times greater at risk than who don't have difficulty. Whereas respondent who don't have abundance of food are 2.633( $\mathrm{CI}=1.165-5.950, \mathrm{p}=0.017)$ times higher at risk of developing PTSD then who have abundance of food. Likewise, respondent who have no asses to psychological tutorship are $2.836(\mathrm{CI}=1.035-7.768, \mathrm{p}=0.036)$ times more 
likely to develop PTSD then who have some psychological tutorship about PTSD and respondent who were displaced after earthquake were $2.344(\mathrm{CI}=1.043-5.265, \mathrm{p}=0.039)$ times at higher risk of developing PTSD

Table 4: association of PTSD with different factors

\begin{tabular}{|l|l|l|l|}
\hline Variables & Category & Unadjusted OR & p-value \\
\hline \multirow{2}{*}{ Age } & Early adolescents & $2.615(1.52-5.3939)$ & $0.018^{*}$ \\
\cline { 2 - 4 } & Middle adolescents & 1 & \\
\hline \multirow{2}{*}{ Economic Difficulty } & No & 1 & $0.001^{*}$ \\
\cline { 2 - 4 } & Yes & $0.855(0.806-0.907)$ & \\
\hline \multirow{2}{*}{ Abundance of food } & No & $2.633(1.165-5.950)$ & $0.017^{*}$ \\
\cline { 2 - 4 } & Yes & 1 & \\
\hline \multirow{2}{*}{ Psychological Tutorship } & No & $2.836(1.035-7.768)$ & $0.036^{*}$ \\
\cline { 2 - 4 } & Yes & 1 & \\
\hline \multirow{2}{*}{ Displacement } & No & 1 & $0.039^{*}$ \\
\cline { 2 - 4 } & Yes & $2.344(1.043-5.265)$ & \\
\hline
\end{tabular}

\section{DISCUSSION}

The prevalence of PTSD in the present study was 10.8 percent and dissociative subtype PTSD was prevalent among 5.6 percent which is almost equal to that of Wenchuan earthquake after six months $(9.7 \%))^{7}$ Similar studies conducted in China, Taiwan, Turkey, Greece, Haiti demonstrated prevalence range from 3.8 percent to 42.02 percent. $^{7-15}$

The difference in prevalence may be due to the tool as other study used DSM IV which was more subjective in nature and for this study DSM V an updated version have added three new symptoms: criteria D (Negative alteration on cognition and mood), criteria E (alteration in arousal and reactivity) and criteria A2 (requiring fear or helplessness or horror right after trauma) to improve diagnostic accuracy. It is also notable that in DSM IV diagnose of PTSD was performed by total score but for DSM V every symptoms criteria most be present in respondents. This may have result in lower prevalence of PTSD in this study. The factors like magnitude of earthquake, genetic makeup and period of time after earthquake may also have contributed to the difference occurrence of PTSD. ${ }^{16}$
This study reveals that age is significantly associated with PTSD. Early adolescents have three times higher at risk of developing PTSD than those who were the middle Adolescents. Whereas other studies conducted in Turkey, China, Greece, Taiwan and Haiti showed no significant association between age and PTSD. ${ }^{7-15}$

The findings showed that there was no significant association of PTSD with Social Support however there is significant association between Psychological Tutorship and $\operatorname{PTSD}(\mathrm{p}=0.036)$. It shows that respondents who have no psychological tutorship are 2.83 times more likely to develop PTSD than those who had Psychological tutorship. This finding is concurrent with similar study carried out among adolescents of China after Wenchuan earthquake. ${ }^{7}$

Overall, this study shows 10.8 percent of PTSD after six month of earthquake which is similar to longitudinal study conducted among adolescent after six month of Wenchuan earthquake $(9.7 \%))^{7}$ Other studies conducted after 1,2 and 3 years of earthquake showed 14, 36 and 59 percent respectively.

\section{CONCLUSION}

Eleven percent of the secondary level students of Chautara Municipality had Post Traumatic Stress Disorder symptoms (PTSD) of which half of them had dissociative subtype PTSD. Younger adolescents were more prone to development of PTSD then older one. Earthquake exposures like financial constraints after earthquake, food deficiency, displacement due to earthquake were the major factors associated with the development of PTSD. Psychological tutorship for PTSD is found to be protective factor for PTSD development in adolescents. Appropriate psychological tutorship should be provided to every secondary level student with trauma to prevent the development of PTSD. Screenings for PTSD and appropriate treatment facility should be provided to traumatized students.

\section{REFERENCES}

1. Post traumatic stress disorder: Merriam webster com, (20 Dec. 2015). Available from: http://www.merriam-webster.com/ medical/post-traumatic stress disorder.

2. Mayoclinic, org. Post traumatic stress disorder (PTSD): Mayo clinic,[15 July 2015]. Available from: http://www. mayoclinic.org/diseases-conditions/post-traumatic-stress-disorder/basics/definition/con-20022540

3. Elhai JD, Layne CM, Steinberg AM, Brymer MJ, Briggs EC, Ostrowski SA, Pynoos RS. Psychometric properties of the UCLA PTSD reaction index. Journal of traumatic stress, $2013 \mathrm{Feb}$ 1; 26(1):10-8. doi:10.1002/jts.21755

4. Fink MD, Harris W, Kessler R, Lanius R, Loewenstein RJ, Putnam FW, Warshaw CL. Report of the American psychiatric association task force on the biopsychosocial consequences of childhood violence.

5. United State geological survey of Lumjung, Nepal,[2015 Oct].Available from http://earthquake.usgs.gov/ Earthquakes/ event page/us2000292y/general_summary

6. UN Office for the coordination of humanitarian affairs of Nepal. Earthquake; district: Profile-Sindhupalchok, [updated 2015 may;cited2015 Oct].Available from http://reliefweb.int/report /nepal/nepal-earthquake-district-profile-sindhupalchok-08052015.

7. Zhang Z, Ran MS, Li YJ, Ou JI, Gong RR, Li RH, Prevalence of post-traumatic stress disorder among adolescents after 
the Wenchuan earthquake in China. Psychological Medicine, 2012; 42(08):1687-1693

8. Aydil B. Post-traumatic stress disorder in turkish child and adolescent. Child and Adolescence Mental Health, 2008; 13(3)2:134-139.

9. Dell'OssoL, Carmassi C,'StrattaC, Massimetti G, Akiskal KK, Akiskal HS, et al. Full and partial ptsd among young adult survivors: gender differences. Font Psychaitry, 2011 ;131(3):79-83.

10. Goenjian AK, Walling D, Steinberg AM, Karayan I, Psy D, Najarian LM,et al. Prospective study of posttraumatic stress and depressive reactions among treated and untreated adolescents. Am J, 200; 162:12. Available from :Am J http://ajp. psychiatryonline.org Psychiatry, 162:12, December 2005

11. Roussos A,Goenjian AK, Steinberg A M, Sotiropoulou C, Kakaki M, Kabakos C,et al. Posttraumatic stress and depressive reactions among children and adolescents in Ano Liosia, Greece. Am J Psychiatry, 2005; 162:530-537

12. Derivois D, Mérisier G, Cénat G, Jude M, Castelot V. Symptoms of posttraumatic stress disorder and social support among children and adolescents. J Loss and Trauma, 2014;19(3):202-212.

13. Hsu CC, Chong MY,Yang P, Yen CF, Posttraumatic stress disorder among adolescent earthquake victims in Taiwan. J Am Acad Child Adolesc Psychiatry, 2002; 41(7):875-881.

14. Fu Y, Chen Y, Jin Wang J, Tang X, He J, Jiao M, Yu C,You G, et al. Analysis of prevalence of PTSD and its influencing factors among college students after the Wenchuan earthquake. Child Adolesc Ment Health, 2013; 7:1

15. Silvestre G, Anacreon P, Theodore M, Silvestre E, Dubus E. Risk factors for posttraumatic stress disorder in haitian students. Sci Res, Psycholog, 2014; 5:849-858 Available from http://www.scirp.org/journal/psychhttp://dx.doi. org/10.4236/psych.2014.58096

16. Friedman MJ. Finalizing PTSD in DSM 5: Getting here from there and where to go next. Journal of Traumatic Stress, 2013 Oct 1; 26(5):548-56. 